\title{
Antropologia e Pós-Colonialismo: focando as castas na Índia
}

\author{
Andreas Hofbauer \\ Universidade Estadual Paulista Júlio de Mesquita Filho, Marília, São Paulo, Brasil \\ E-mail: andreas.hofbauer@uol.com.br
}




\section{Resumo}

O artigo propõe-se a analisar convergências e divergências entre duas "tradições de análise" acadêmicas frente ao tema da alteridade: antropologia e pós-colonialismo. Ao exemplo do debate em torno das castas na Índia, busca-se ilustrar os alcances e os limites dos enfoques antropológicos e pós-coloniais. Como ambas as abordagens oferecem potencialidades de análises valiosas, o autor sugere tratá-las como complementares e propõe a elaboração de uma perspectiva analítica plural.

Palavras-chave: Antropologia. Póscolonialismo. Diferença. Desigualdade.

\section{Abstract}

This article analyses the convergences and divergences between two academic 'analytic traditions' on the subject of alterity: Anthropology and Postcolonialism. Setting out from the example of the caste debate in India, it seeks to illustrate the scopes and limits of the anthropological and postcolonial approaches. Since both offer the potential for valuable analyses, the author suggests treating them as complementary and proposes the elaboration of a plural analytical perspective.

Keywords: Anthropology. Postcolonialism. Difference. Inequality.

ILHA 


\section{Introdução}

$\mathrm{D}$ esde a virada do milênio, críticas e preocupações pós-coloniais começaram a se fazer cada vez mais presentes em textos produzidos por cientistas sociais brasileiros, inclusive por antropólogos (Costa, 2006; Carvalho, 2001). À primeira vista, as preocupações e os "objetos" de pesquisa que estão no centro dos estudos pós-coloniais e antropológicos podem parecer muito semelhantes. Acredito que há, de fato, diversas convergências entre eles, mas há também divergências não desprezíveis nestas duas "tradições". Refletir sobre os pontos de contato e de atrito é objeto deste pequeno ensaio. Ao exemplo de um caso empírico específico, buscarei na segunda parte deste ensaio abordar um tópico que pode ser considerado clássico na tradição antropológica e é também caro à crítica pós-colonial: a questão das classificações e das fronteiras.

Localizo uma concordância em no mínimo dois posicionamentos fundamentais: tanto a antropologia clássica quanto a crítica pós-colonial direcionam seus olhares e preocupações para grupos marginalizados pelo processo da expansão colonial; ambas têm apontado para o fato de que as concepções ocidentais hegemônicas têm impossibilitado um acesso adequado ao mundo dos colonizados: a antropologia desenvolveu, desde muito cedo, estratégias analíticas específicas para explicar/ compreender as formas de viver e pensar de grupos não ocidentais; já os pós-coloniais têm chamado, em primeiro lugar, a atenção para os processos de inferiorização, opressão e exploração diretamente vinculados à imposição de uma "episteme colonial".

Qual é, então, a razão por detrás das críticas correntes e, por vezes, bastante ácidas dos pós-coloniais à antropologia (Rea, 2010, p. 182 ) e por que os trabalhos antropológicos, suas teorias e métodos, 
são geralmente ignorados nas obras tidas como fundacionais do póscolonialismo? Como entender, de outro lado, a reação enérgica por parte de antropólogos renomados às reflexões críticas pós-coloniais acerca da maneira como as diferenças culturais têm sido abordadas pelos cânones da antropologia?

\section{Linhagens e Trajetórias}

É inegável que a história da antropologia esteja conectada à expansão colonial europeia. No entanto, havia, evidentemente, diferentes formas e níveis de envolvimento. É sabido, por exemplo, que Malinowski evitava a convivência com os missionários que atuavam na Melanésia e não deixava de criticá-los por destruírem as tradições culturais e o equilíbrio psicológico dos nativos (Diário de Malinowski, 1956, p. 41); ao mesmo tempo, anos mais tarde, propagaria o "lado prático" da antropologia como uma forma eficaz de "social engineering" no contexto colonial com o objetivo de convencer a Fundação Rockefeller a subsidiar o International African Institute (Kuklick, 1991, p. 210). Também a atitude de Evans-Pritchard de atender à solicitação da administração colonial que lhe pediu para elaborar um estudo etnográfico entre os Nuer, pode ser vista com suspeita, mesmo que este tenha explicado sua decisão com o argumento de evitar o extermínio daquela população que "criava problemas" aos administradores coloniais (Douglas, 1980, p. 40).

E houve também alguns - poucos - antropólogos, como Risley, cujo posicionamento frente à intervenção colonial não deixava muitas dúvidas. Contratado como "Census Commissioner" e encarregado de organizar o quarto censo decenial da Índia (1901), aplicava largamente métodos antropométricos com o objetivo de comprovar que a divisão da sociedade em castas teria uma razão mais profunda. Ao empregar a concepção de raça biológica, tal como vinha sendo desenvolvida na Europa no final do século XIX, ao contexto indiano, buscava não somente explicar diferenças detectadas, mas contribuía também para justificar desigualdades de ordem social e econômica entre os grupos (cf. abaixo). Ao mesmo tempo, não faltam também relatos 
históricos, em diversos lugares do mundo, sobre fricções e conflitos entre administradores coloniais e antropólogos, não raramente, percebidos pelos primeiros como uma ameaça aos projetos coloniais ${ }^{1}$.

Com todas as ambiguidades e atividades duvidosas que os primórdios da prática antropológica apresentam, Will Rea chega à conclusão de que a antropologia desempenhou um papel relativamente ínfimo na implementação e manutenção de regimes coloniais. Já para a execução do trabalho antropológico e para a consolidação da disciplina, a relação dos cientistas com o colonialismo teria sido fundamental. Este apoio não se limitava apenas à utilização da infraestrutura montada pelos regimes coloniais e, portanto, ao apoio logístico com o qual os antropólogos podiam contar em campo. Rea entende que o poder europeu, veiculado tanto via discursos quanto por meio de práticas concretas, foi sempre uma parte intrínseca da realidade que os antropólogos buscavam compreender. O que é paradoxal, para este antropólogo britânico, é o fato de os modelos desenvolvidos pelos antropólogos não terem feito praticamente nenhuma referência a esta realidade da dominação europeia (Rea, 2010, p. 186).

No meu modo de ver a questão, aquilo que Rea descreve como um paradoxo não se explica somente por uma "cegueira" ou "amnésia histórica" (Rea, 2010, p. 186, 187) da parte dos antropólogos. As teorias e conceitos elaborados e usados pelos "clássicos" revelam que os antropólogos partiam também, inicialmente de forma explícita e posteriormente de forma cada vez mais implícita, de uma premissa que dividia o mundo entre "espaços, vivências marcadas pela modernidade" e "espaços, vivências não afetadas pela modernidade". As históricas oposições binárias entre primitivo e civilizado, simples e complexo (às vezes, colocadas entre aspas) ou ainda sociedades frias versus sociedades quentes são testemunho deste passado fundacional da disciplina.

E embora a antropologia tenha feito, há muito tempo, uma profunda autocrítica acerca do pensamento fundacional evolucionista, o instrumental teórico e conceitual desenvolvido a partir do início do século XX não pôs em xeque a dicotomia entre modernidade e nãomodernidade. Ao contrário: culturalistas, funcionalistas e estruturalistas buscavam, por meio de conceitos analíticos, tais como padrões, 
funções e estruturas, detectar lógicas de sociabilidades que seriam substancialmente diferentes da(s) do mundo moderno.

As unidades de análise empregadas nas grandes monografias clássicas traziam a marca do chamado "nacionalismo metodológico"2 que pressupunha a existência de fronteiras claras entre as sociedades estudadas. Se esta postura se expressava também na crença implícita numa congruência entre fronteiras geográfico-espaciais, fronteiras grupais e de repertórios socioculturais (Gupta; Ferguson, 1992), os antropólogos concentravam-se, durante muito tempo, na análise daquilo que Barth chamaria de "cultural stuff": eles tendiam a conceber as fronteiras grupais como uma consequência direta dos limites da "vigência" dos diferentes sistemas culturais. O foco do interesse viria a ser fenômenos como o da estabilidade, homogeneidade, coerência, além de significados, valores e símbolos; já variabilidades internas às unidades estudadas, conflitos e poder permaneciam tópicos negligenciados (Lentz, 2016, p. 8, 13).

Essa estratégia analítica, detectada por Trouillot (2002) e Lentz (2016), visava ainda outro objetivo fundamental: a consolidação da noção de culturas ${ }^{3}$ como entidades coesas e holísticas permitia a elaboração de uma crítica vigorosa aos determinismos evolutivo e racial-biológico responsáveis por modelos explicativos que justificavam a hierarquização de grupos humanos. Na medida em que as análises antropológicas mostravam a coerência desses outros sistemas culturais, constituíam e valorizavam a existência de outros sistemas de cognição, outras cosmovisões, religiões e epistemes.

O relativismo cultural clássico é, portanto, fruto de um contexto histórico em que a crítica antropológica procura superar as narrativas hierarquizantes e discriminatórias, de um lado, e busca convencer os seus leitores ocidentais de que existem outras maneiras valiosas de viver em sociedade fora da modernidade. No bojo desta reflexão, alguns autores - por exemplo, Bastide $\left(1960^{4}\right)$ - desenvolveram a noção de "resistência cultural", valorizando assim a persistência de particularismos - não modernos - frente à expansão do mundo moderno-capitalista. O combate aos preconceitos predominantes na sua própria sociedade pode ter induzido a maioria dos antropólogos 
a deixar de abordar o tema do conflito, nem eventuais formas de discriminação internas às culturas pesquisadas ou ainda valorizações e desvalorizações de determinadas características fenotípicas (Beer, 2002, p. 15); outra consequência desta estratégia analítica e narrativa, que foca e exalta a existência de diferenças essenciais, é a omissão diante das relações entre o mundo dos colonizadores e o dos colonizados ${ }^{5}$.

O modelo mítico da pesquisa de campo, elaborado cuidadosamente nas narrativas de Malinowski acerca de suas experiências nas ilhas Trobriand, é outra referência importante que deu respaldo às dicotomias presentes na reflexão antropológica desde seus primórdios. A imagem produzida na Introdução de sua famosa monografia é impactante: após o afastamento do navio que o deixou na pequena ilha, o pesquisador montou sua barraca no meio de uma aldeia para, desta forma, poder observar e participar da vida cotidiana dos insulares. Esse "ideal" propagado pelo próprio Malinowski retrata um cenário em que o antropólogo "rompe" com o mundo ocidental para "inserir-se" num mundo distante e isolado daquele regido pela modernidade.

Qualquer estudo cuidadoso sobre a fase fundacional da antropologia há de reconhecer que a antropologia clássica acabou endossando e reforçando a ideia que separa e opõe o mundo entre Ocidente e nãoocidente ("resto do mundo", na dicção de Hall) - uma construção dicotômica que estudiosos pós-coloniais como Hall desmascarariam como um dos mecanismos discursivos que visa assegurar relações de dominação e subjugação. Se a sociologia tornar-se-ia a ciência comprometida com os ideais do projeto da modernidade (perceptível, por exemplo, em recortes clássicos como os da estrutura de classes e estratificação social, abordadas a partir de valores tais como os da igualdade e liberdade individual), a antropologia especializar-se-ia em estudar aquelas sociedades que, supostamente, (ainda) não foram atingidas pela lógica societal da modernidade ocidental.

Ao olhar agora para a história da crítica pós-colonial, é possível perceber que esta toma forma em outro contexto histórico, mais de um século após a fundação das primeiras associações antropológicas na Europa e nos EUA. Princípios do pensamento pós-colonial podem ser encontrados - como é sabido - por exemplo, nas reflexões críticas 
de autores relacionados ao pan-africanismo, à négritude ou na obra de Fanon que, para muitos, tornou-se uma referência icônica fundamental. No entanto, é o livro Orientalismo (1978) de E. Said que acaba sendo apontado como obra fundacional do pós-colonialismo, devido à maneira engenhosa como este autor traz à luz os nexos entre criação de um conhecimento sobre o Oriente e legitimação do poder colonial. Ao focar as relações entre discurso, exercício do poder e estabelecimento de fronteiras entre "nós" e os "outros", Said conjuga aqueles elementos que se cristalizariam como principais características do pensamento pós-colonial. Impulsos fortes da crítica literária, reflexões foucaultianas sobre a relação entre discurso, saber e poder, o desconstrutivismo derridariano, reavaliações gramscianas acerca da noção da hegemonia, inspirações psicanalíticas lacanianas são algumas das referências recorrentes do ecletismo teórico presente nas obras pós-coloniais.

A cientista política alemã, Ina Kerner, localiza três grandes eixos temáticos em torno dos quais a crítica pós-colonial tem se articulado. Partindo da compreensão de que o mundo contemporâneo é, de fato, resultado de processos históricos torna-se necessário, nas reflexões sobre o mundo, levar a sério: 1) as influências do colonialismo europeu (inclusive, no que diz respeito aos padrões de pensamento) sobre as estruturas políticas, sociais e econômicas; 2) as interdependências e imbricamentos (entanglements) globais, históricos e contemporâneos; 3 ) as relações de poder e assimetrias entre norte e sul. Kerner chama a atenção para o fato de que em todas estas três dimensões de análise, os aspectos discursivos assumem um papel de destaque (Kerner, 2016, p. 164). O sociólogo brasileiro Sérgio Costa, por sua vez, enfatiza as críticas de ordem conceitual e teórica que vêm acompanhando essa mudança de enfoque. Para ele, o alvo central da crítica pós-colonial são as teorias clássicas da modernização. Três preocupações interligadas marcariam estes questionamentos fulcrais: 1) a crítica ao modernismo enquanto uma teleologia da história (i.é., a crítica à ideia segundo a qual a transição para a modernidade se dá de uma forma linear e uniforme); 2) a tentativa de fugir aos essencialismos e a consequente busca e valorização de um lugar de enunciação "hibrido"; 3 ) a crítica à concepção clássica do sujeito (concebido como uma entidade autocentrada) na tradição das Ciências Sociais (Costa, 2006, p. 85). 
As avaliações destes comentadores deixam claro que, diferentemente da antropologia clássica, a crítica pós-colonial tem como ponto de partida não os supostos mundos não-modernos, mas muito mais o próprio mundo ocidental, suas históricas formas de intervenção militar, política e econômica e suas representações acerca dos não ocidentais. Tentam mostrar que uma das maneiras mais eficazes da dominação colonial e contemporânea (entende-se que com o fim do colonialismo político não foram abolidas suas formas de dominação e exploração) baseia-se na disseminação de uma episteme própria que tem como uma de suas pedras angulares uma divisão conceitual rigorosa entre o mundo da modernidade e os mundos não modernos. A desconstrução dos discursos hegemônicos tornou-se, portanto, um dos instrumentos analíticos primordiais. Assim, autores como Stuart Hall querem mostrar como estes discursos, que, segundo ele, reduzem a história moderna a uma ocidentalização paulatina e heroica do mundo, omitem o fato de que o processo da expansão colonial fundiu e mesclou, de forma violenta, diferentes historicidades e temporalidades (Hall, 2003, p. 113115). A própria elaboração da concepção clássica do sujeito iluminista cartesiano seria tributária de um ideário construído no momento da expansão colonial, uma "autorrepresentação" que visaria a afirmar e enaltecer um self europeu em oposição aos colonizados em ultramar (Hall, 2001 [1992], p. 23-33) . O poder atribuído aos discursos refletese não raramente também no farto uso de metáforas sofisticadas e na criação de novos conceitos (cf., por exemplo, a obra de Bhabha).

A "corrente" decolonial, cujos protagonistas fazem questão de delimitar-se dos pós-coloniais ${ }^{7}$, enfatizam, talvez até mais do que os ulteriores, a questão epistêmica. O termo "colonialidade do poder" cunhado por Aníbal Quijano aponta para um padrão estrutural específico da modernidade que teria sido construído a partir da "conquista" das Américas (ponto enfatizado pelos decoloniais, que acusam os pós-coloniais anglo-saxônicos de terem omitido esta parte fundamental da história do colonialismo). A hegemonia da Europa teria sido fundamentada por esta intervenção: colonialidade, exploração capitalista e imposição de classificações étnicas e raciais aparecem, na análise deste sociólogo peruano, como fenômenos intrinsecamente interligados (Quijano, 2014, p. 285). 
O semiótico argentino Walter Mignolo (2003, p. 30) entende igualmente a "colonialidade" como o lado obscuro e, ao mesmo tempo, necessário da modernidade. Ele mostra-se extremamente cético em relação a contribuições positivas do pensamento ocidental moderno; critica os pós-coloniais anglo-saxônicos por terem baseado suas reflexões em autores ocidentais: desaprender o saber colonial seria a primeira exigência imprescindível para poder descobrir/construir outros saberes.

A desconstrução dessa polaridade (West/rest) seria, portanto, o primeiro passo para, de um lado, se fazer uma autocrítica à história colonial expansionista do Ocidente e, de outro, reconhecer e fortalecer formas de sociabilidade que têm sido sistematicamente discriminadas e oprimidas pela episteme colonial. Nesse ponto há ampla concordância entre pós-coloniais e decoloniais.

Chama-se também a atenção para o fato de as narrativas anticolonialistas clássicas conceberem o colonialismo, acima de tudo, como um aparato de dominação que remete ao passado, enquanto "[...] as diferentes vertentes do pós-colonialismo têm como objetivo (de análise e de contestação) os seus efeitos e a operação no presente." (Restrepo, 2007, p. 2,3). De forma semelhante, Hall faz um apelo para se recusar aquilo que denomina “[...] distinção falsa e impeditiva entre colonização enquanto sistema de governo, poder e exploração e colonização enquanto sistema de conhecimento e representação que está sendo recusada [...]" (Hall, 2003 [1998], p. 119); e o filósofo colombiano Castro-Gómez critica o fato de que "as narrativas anticolonialistas [dos anos 1960 e 1970] jamais indagaram o status epistemológico de seu discurso" (Hall, 1998, p. 171, 172) ${ }^{8}$. Vários autores, por exemplo, Hall, Gilroy, Castro-Gómez, fazem, portanto, questão de chamar a atenção para o fato de que a luta anticolonial clássica ocorreu ainda dentro da episteme colonial (por meio da "reificação", isto é, por meio da fixação da suposta diferença entre o colonizador e o colonizado) e dedicamse à elaboração de soluções teóricas que permitam servir de base a lutas contra-hegemônicas que sejam distintas de uma mera inversão da valorização do par conceitual "o Ocidente e o resto". Percebe-se aqui também, que a análise pós-colonial, diferentemente da tradição antropológica clássica, exige um posicionamento político explícito, uma 
vez que se entende que a articulação de um saber - qualquer saber - é sempre um ato de posicionar-se.

\section{Estreitando o Foco de Comparação}

A maior parte dos estudos pós- e decoloniais dedica-se à análise e, ao mesmo tempo, à denúncia dos diversos métodos e estratégias por meio das quais o Ocidente foi expandindo sua influência sobre o globo e, dessa forma, explorando e oprimindo os colonizados. O foco principal, na maioria dos textos, é a desconstrução, a denúncia daquilo que é entendido como erros e injustiças históricos - uma preocupação que demonstra a adesão implícita a uma episteme (para usar a terminologia pós-colonial/decolonial) que visa a unir o valor da igualdade com o do respeito à diferença. Relativamente pouco (em comparação com as monografias antropológicas clássicas) fica-se sabendo sobre o mundo dos colonizados ${ }^{9}$; e raramente são analisadas situações de opressão (incluindo eventuais processos de colonização) anteriores à época colonial ${ }^{10}$. Aqueles estudos, que acrescentam aos seus objetivos o "resgate" de outras epistemes, costumam ignorar as experiências e saberes antropológicos nesse quesito e evitam em geral atribuir à cultura uma dimensão estruturante e cognitiva. Tampouco se costuma distinguir entre diferentes dimensões da prática cultural, tal como apontadas por Carneiro da Cunha com os termos "cultura sem aspas" e "cultura com aspas"11, nem distinguem, como Eriksen (2004, p. 161), entre identificações "imperativas" e "situacionais"12 nos processos que marcam o que Hall e outros pós-coloniais entendem como posicionamentos ${ }^{13}$.

"Nada surge a partir de nada", escreve Eriksen, parodiando Parmênides, para chamar a atenção para o fato de que as identificações são guiadas ou, ao menos, mediadas por símbolos e significados que fazem parte da vivência cotidiana dos sujeitos; opõe-se, dessa forma, àquelas análises que tendem a subestimar as forças culturais - frequentemente inconscientes aos agentes sociais - que, de acordo com ele, se manifestam nos processos identitários ${ }^{14}$. Embora reconheça, evidentemente, a importância do agenciamento e o jogo de poder que 
permeia os processos de identificação, insiste em alertar para as força da culturas, vendo nelas um fator estruturante dos comportamentos e das percepções do mundo: "Diferenças culturais existem e podem tornar-se relevantes mesmo quando elas não são, conscientemente, 'tornadas relevantes"". E adiante: "Cultura é até certo ponto algo escolhido e construído, mas é também, em grande medida, algo implícito; contém um elemento de sina ou destino" (Eriksen, 2002, p. 5, 7, 8).

Diferentemente desta visão, os pós- e decoloniais tendem a tratar a cultura - quando não descartam totalmente o conceito de cultura - como um marco diferenciador (cf. crítica de Sahlins abaixo) que adquire importância social e política naqueles discursos que evocam processos de diferenciação. Assim, Nicholas Dirks refere-se à cultura como um "efeito do poder", o qual este antropólogo norte-americano, profundamente marcado pelas teses pós-coloniais, concebe como um produto do contexto colonial:

Eu tenho olhado para a cultura principalmente como um efeito do poder e tenho insistido que as asserções acerca de diferenças culturais têm sido produzidas em grande medida pela longa história da dominação colonial (Dirks, 2001, p. 313$)^{15}$.

Lila Abu-Lughod foi um passo além. Refere-se à cultura como uma "ferramenta essencial de fabricação de alteridades"16, cujo papel histórico avalia como não substancialmente diferente daquele do seu conceito predecessor - a raça -, e sugeriu, consequentemente, substituir esta categoria analítica. Propôs o uso dos conceitos discurso ou prática, uma vez que, segundo ela, estes não evocariam homogeneidade, holismo, binarismos e/ou fronteiras nítidas, mas focariam outras dimensões que julga mais importantes: dinâmicas, subjetividades, processos; desigualdades, relações de dominação (Abu-Lughod, 1991, p. 143-145).

São posturas como essas que levaram antropólogos, como Sahlins e Ortner - que não abrem mão de uma concepção "mais clássica" de cultura, buscando conjugá-la com usos subjetivos e interessados ("agency") das suas estruturas estruturantes - a acusar os pós-modernos, pós-estruturalistas e pós-coloniais de esvaziarem o conceito de cultura 
("thinning culture") e de transformar a alteridade em "efeito de discursos" (Ortner, 2006, p. 50-58) ${ }^{17}$. Sahlins afirma que essa "visão de vanguarda" por ele identificada reduz a cultura a um mero "conceito diferenciador" ("differencing") ${ }^{18}$, cuja única função seria marcar (criar) diferença. Nessa perspectiva analítica, a noção de poder seria transformada numa espécie de "buraco negro intelectual" que engole os mais diversos conteúdos culturais (Sahlins, 2002, p. 20) ${ }^{19}$.

As oposições entre abordagens antropológicas e pós-coloniais rapidamente esboçadas aqui podem parecer um tanto exageradas. Sabese que a crítica pós-moderna - que, como mostrou Boaventura Santos (2004, p. 9), compartilha com a crítica pós-colonial muitas inspirações teóricas - fez-se também presente na disciplina antropológica e deixou suas marcas. Existem hoje vários estudos pós-modernos e pós-coloniais de autoria de antropólogos. O que quero tematizar aqui são os diferentes cânones que se expressam na maneira como o fenômeno da alteridade é abordado. Se o foco da análise for a desconstrução dos discursos hegemônicos concebidos como responsáveis pela inferiorização e racialização dos colonizados, a pesquisa nos trará provavelmente pouca informação acerca das bases cognitivas e ético-morais que orientam o olhar e os comportamentos dos colonizados; não raramente, estudos que seguem esta perspectiva negam implicitamente a existência de uma base estruturante desta ordem. Se hábitos, valores e cosmovisões locais estiverem no centro da análise, não é de se estranhar que a reflexão sobre as imposições coloniais, que podem, evidentemente, ter contribuído para a formação e transformação das bases estruturantes locais, tende a ganhar um papel subordinado e pode talvez nem ocorrer.

Acredito que os dois vieses caracterizados não são incompatíveis: não se excluem mutuamente; prefiro encará-los como complementares. No entanto, para poder explorar as potencialidades analíticas de ambos, parece, em primeiro lugar, necessário reconhecer o fato de eles privilegiarem focos diferentes, tendo cada um deles seu alcance, mas também suas limitações interpretativas.

Desde muito cedo os antropólogos mostraram-se interessados e fascinados pela compreensão de sistemas classificatórios que fossem diferentes dos ocidentais. Seu estudo era encarado também como 
um meio para se ter acesso a diferentes dimensões profundas dos pesquisados (cognição, parentesco, formas de pensar o mundo). Boas, por exemplo, investiu na análise das diferentes percepções das cores e buscava decifrar o enigma dos "sons alternantes": descobriu que os registros alternantes de uma mesma palavra de uma língua desconhecida aos cientistas ocidentais não se deviam a um suposto "primitivismo" dos seus falantes, mas eram consequência direta do repertório fonético que marcava as línguas maternas dos pesquisadores e, consequentemente, da sua capacidade de ouvir (registrar) aqueles sons que não faziam parte do seu repertório linguístico (Boas, 2004, p. 98-104).

Durkheim e Mauss (1903), no entanto, procuravam decodificar os sistemas classificatórios que regeriam a organização social nas chamadas sociedades "primitivas" ou "arcaicas". Nos dois casos, as análises acerca dos sistemas classificatórios foram elaboradas sem que fossem investigadas as relações de poder. Assim, nos estudos clássicos, que pressupunham a existência de uma coincidência entre fronteiras culturais e fronteiras grupais, a análise dos sistemas classificatórios não envolvia nenhum interesse específico por conflitos sociais e/ou processos discriminatórios, nem por aqueles internos ao grupo - e muito menos por aqueles entre o grupo e possíveis forças externas sobre a organização social em questão. Não se investia em saber como "sistemas classificatórios nativos" [dos colonizados] se relacionavam com "sistemas classificatórios" dos colonizadores [episteme colonial] ${ }^{20}$ : o objetivo declarado era entender a lógica do sistema ao qual se atribuía uma "vida própria".

Foi com a introdução da noção de identidade étnica nas reflexões antropológicas que as abordagens sobre classificações e fronteiras incorporariam preocupações mais nitidamente políticas. É sabido que F. Barth (1969) foi um dos primeiros a chamar a atenção para o fato de que as fronteiras étnicas não deviam ser vistas como uma consequência direta das fronteiras culturais. Seus questionamentos e reflexões abriram o caminho para incluir nas análises o olhar dos próprios pesquisados sobre as fronteiras, ou melhor, sobre aquilo que os 
diferencia dos "outros". Reconhece-se, assim, subjetividades, escolhas e interesses; no entanto, a direção do olhar permanece situada, sendo formulada de dentro para fora e possíveis influências externas (por exemplo, provindas de regimes coloniais) sobre as "escolhas" dos "emblemas de diferença" não mereceriam destaque neste trabalho clássico de Barth ${ }^{21}$.

Já as contribuições pós-coloniais referentes às classificações realçam, acima de tudo, os efeitos da ação colonial. O foco voltado para a intervenção colonial e, fundamentalmente, para o discurso colonial permite mostrar como os poderes coloniais conseguiram criar alteridades inferiorizadas - um procedimento que é denunciado como uma técnica fundamental para controlar os colonizados (Said, 1978; Bhabha, 1994). Contribui ainda para revelar que as intervenções coloniais foram decisivas na disseminação da noção "ocidental" de grupos, etnias e tribos (unidades homogêneas com fronteiras bem acabadas $^{22}$ ) em contextos onde as solidariedades e os pertencimentos eram múltiplos e fortemente contextuais. Dessa forma, muita atenção costuma ser dada às ações das administrações coloniais que, como instrumento de controle das populações colonizadas, promoviam registros e censos. Ao mesmo tempo, constata-se que os estudos que se inspiram nas diretrizes pós- e decoloniais desenvolveram pouco interesse em investigar as relações que se estabelecem entre sistema classificatório imposto e sistemas classificatórios locais.

Na medida em que uma das grandes preocupações é o poder colonial sobre a criação e imposição de fronteiras e classificações étnicas e raciais, os sistemas classificatórios locais e os modos de sua aplicação no embate com a episteme colonial não costumam estar no centro das indagações pós-coloniais. Já a questão da(s) fronteira(s) ganhou destaque no pensamento pós-colonial não somente para entender a ação do poder colonial. Avalia-se que para construir estratégias que permitam superar a episteme colonial é imperioso repensar o fenômeno das fronteiras e criar novos modos de lidar com elas. As propostas apresentadas envolvem construções teóricas sofisticadas que vão desde usá-las em favor dos oprimidos ("essencialismo estratégico") até desestabilizá-las e borrá-las. 


\section{Castas na Índia}

Nas minhas pesquisas mais recentes sobre os siddis em Karnataka - afrodescendentes cujas histórias apresentam semelhanças, mas também divergências em relação às dos quilombolas brasileiros comecei a deparar-me com o tema complexo das castas indianas; afinal, os siddis foram, de certo modo, também incorporados a este sistema de organização social, que já foi caracterizado como "símbolo central da sociedade indiana" (Dirks, 2001, p. 3).

Em todos os discursos que visavam ao fim do domínio colonial e, sobretudo, nas discussões acerca da construção de um país independente, as castas eram uma referência constante: ou eram lembradas como uma característica particular da sociedade indiana que a diferenciava da dos colonizadores ou eram citadas como uma aberração societal que a sociedade livre dos colonizadores teria de superar. Assim, os eminentes líderes políticos Gandhi e Ambedkar discordavam profundamente a respeito do valor social das castas (num ponto, no entanto, concordavam: ambos lamentavam as profundas desigualdades sociais entre as castas e entendiam a intocabilidade como um fenômeno inaceitável). Mohandas Karamchand - Mahatma Gandhi - via o sistema dos varnas ${ }^{23}$ diretamente vinculado a princípios morais (manifestos em textos sagrados milenares) que este grande líder concebia como mais nobres do que aqueles que regiam as sociedades de classe ocidentais baseadas no materialismo capitalista (Gandhi, 1920, p. 3). Se este discurso conseguia, de um lado, incentivar um espírito nacionalista contra a presença britânica, de outro, tendia a amenizar e justificar desigualdades internas ${ }^{24}$.

Já Bhimrao Ramji Ambedkar, ele próprio de uma família "intocável", concebia, desde muito cedo, as castas e as discriminações relacionadas a elas como elemento integrante e inseparável daquilo que se convencionava conceber como hinduísmo ${ }^{25}$. Ambedkar, que se tornaria o primeiro ministro da justiça e principal mentor da Constituição Indiana, não via meio de reformar o sistema das castas e voltou-se, consequentemente, a combater os supostos fundamentos (saberes fixados em textos sagrados) do hinduísmo que, para ele, 
não passavam de um acúmulo de preceitos, comandos e proibições (Ambedkar, 1936, p. 50) ${ }^{26}$.

Se na luta de Gandhi contra o regime colonial e pela construção de um espírito nacional, a recuperação dos antigos valores religiososculturais que teriam caído em decadência ganhava destaque, o pensamento e as ações de Ambedkar orientava-se basicamente por valores entendidos como universais, comprometidos com os ideais da modernidade (ocidental). Não há dúvida: Ambedkar apostava na força das leis para superar desigualdades e discriminações.

A Constituição (1950), para cuja elaboração Ambedkar deu contribuição fundamental, aboliu finalmente o status da intocabilidade e baniu atos discriminatórios baseados em critérios como religião, raça, sexo e também casta. Reconheceu, ao mesmo tempo, a existência de castas, na medida em que alguns artigos (por exemplo, art. 46) incentivavam políticas de Estado focadas que tivessem como objetivo melhorar a situação social e econômica das castas inferiores e de grupos tribais, buscando protegê-los de discriminações. Foi a partir daí que a Índia independente começou a implementar um dos primeiros e mais abrangentes sistemas de ação afirmativa: cotas e subsídios para aqueles grupos que são reconhecidos pelo Estado como castas ou tribos inferiorizadas (Scheduled Castes e Scheduled Tribes). Com a ampliação cada vez maior desse sistema de reservation, este ganharia uma enorme importância no jogo político-partidário, alimentado, por um lado, por pressões de líderes de castas por subsídios, e por promessas de políticos, de outro, de maneira que, escreve Bayly no final do século $\mathrm{XX}$, seria suicídio eleitoral para qualquer partido propor sua extinção (Bayly, 2001 [1999], p. 303). Mas as castas não são somente moeda nas disputas político-partidárias; elas continuam, de diversas formas e com pesos diferentes, a influenciar hábitos e costumes (acima de tudo, as escolhas matrimoniais) de grande parte da população indiana - especialmente nos interiores do país.

Além do debate, entre políticos e cientistas sociais, em torno da relevância social atual das castas, há também discussões acadêmicas acirradas sobre a história mais remota das castas que gostaria de esboçar aqui. A maioria dos pesquisadores entende hoje que o colonialismo 
britânico contribuiu, de forma decisiva, para a remodelação do fenômeno social das castas e para o redimensionamento da sua importância social. Mas há discordâncias profundas no que diz respeito ao teor e ao peso dessa intervenção. A polarização no debate dá-se entre concepções substancialistas que defendem a ideia de que existe algo como um substrato cultural indiano (hindu) e análises marcadamente desconstrutivistas que atribuem às intervenções coloniais a maior responsabilidade pela importância social que as castas têm ganhado na Índia.

As ricas e cuidadosas análises elaboradas por Nicholas Dirks e Susan Bayly sobre as transformações históricas das castas podem ser vistas como exemplos que representam estes dois posicionamentos antagônicos no debate. Se a análise do antropólogo norte-americano Dirks incorpora a perspectiva pós-colonial, a colega britânica opera com um instrumental analítico antropológico "mais clássico". Tanto Dirks quanto Bayly entendem que na Índia pré-colonial (pós-mughal) grandes partes da população ainda não organizavam suas vidas segundo "princípios" de casta (jati e varna ${ }^{27}$ ) e que as fronteiras entre grupos de status eram mais fluidas e ambíguas do que viriam a ser a partir do final do século XIX. Teria havido uma pluralidade de laços de pertencimento e de "unidades de identidade social" 29 . As normas de casta existentes eram aplicadas, de acordo com Bayly, mais como "pontos de referência" a serem negociados e ajustados aos respectivos contextos, e não como "absolutizações unidimensionais" ("one-dimensional absolutes" Bayly, 2001, p. 30).

\subsection{Foco: tradições locais estruturantes}

Susan Bayly estabelece uma relação entre o declínio paulatino do reino dos mughals e um primeiro fortalecimento das identidades de castas já no século XVIII. Novas entidades dinásticas teriam emergido neste vácuo. Nesse contexto de reorganização social e política, conhecimentos antigos, manifestos em textos sagrados, teriam assumido um papel importante, na medida em que os sacerdotes brâmanes, guardiães dos escritos sagrados e desde muito tempo organizados numa estrutura de castas, ganharam cada vez mais influência em diversas cortes. 
A análise de Bayly foca, a seguir, os lentos processos de transformação que, segundo ela, impulsionaram a disseminação do fenômeno social das castas sobre praticamente todo o subcontinente, um processo que teria sido acompanhado por um enrijecimento das fronteiras das castas e uma espécie de universalização dos hábitos e práticas sociais entendidos como característicos de cada um dos grupos. Bayly não nega, neste contexto, o papel da East India Company que começou, a partir de 1820, a exigir de cada vez mais pessoas tributos cada vez maiores.

Teria sido neste contexto que grupos de ascendência nobre e proprietários de terra ligados a castas superiores ("twice-born patricians") começaram a representar-se como defensores de "princípios dhármicos", i.é., incorporaram, cada vez mais, valores e hábitos fixados em diversos textos sagrados cujos guardiães eram tradicionalmente os brâmanes que, como elite letrada local, conseguiam aproveitar o momento da implantação do regime colonial para aumentar sua influência e poder. Convenções rigorosas de casamento, regras de comensalidade e, acima de tudo, um amplo sistema classificatório que divide as coisas e as ações humanas entre puras e impuras eram algumas destas práticas e valores que caracterizavam a casta dos brâmanes e que, de acordo com Bayly, começavam a disseminar-se agora cada vez mais (Bayly, 2001, p. 201, 205).

A análise de Bayly sugere, portanto, que as pressões por pagamento de tributos, que implicaram desestabilidade e insegurança para os proprietários rurais, teriam induzido cada vez mais grupos a redefinirem sua autorrepresentação, recorrendo a e apropriando-se de um saber local associado, inicialmente, somente aos brâmanes. Preocupados com a manutenção de seu status e vantagens econômicas, teriam deixado de definir sua posição social elevada em primeiro lugar com base em suas propriedades rurais e incorporariam agora valores e hábitos dhármicos (típicos do mundo dos brâmanes): impuseram subsequentemente os critérios da pureza e impureza às suas relações sociais, na medida em que começavam a tratar os diversos grupos social e economicamente desfavorecidos (sem posse de terra) como "intocáveis" para, desta forma, deles exigirem a execução de trabalhos considerados "inferiores" e "impuros". 
O acirramento da exploração provocaria também reações entre aqueles grupos que seriam identificados agora como castas inferiores ou intocáveis. Bayly aponta neste contexto para outra questão que considera importante: ela procura mostrar que as formas de resistência, geralmente, não punham em xeque a lógica de castas que estava se impondo. Ao contrário, a maioria dos grupos teria aderido às convenções de pureza e hierarquia e buscava adaptá-las à sua realidade para, desta forma, conquistar vantagens no jogo de poder local e reivindicar um posicionamento mais elevado na hierarquia das castas (Bayly, 2001, p. 232). Aos poucos, o fenômeno das castas tornava-se, assim, uma realidade para a grande maioria dos indianos.

As subsequentes análises de Bayly sobre a segunda parte do século XIX e o início do século XX, não negam o impacto dos discursos dos orientalistas - aqueles cientistas europeus que se autodeclaravam especialistas em assuntos orientais - sobre a remodelação da noção das castas. No entanto, o viés analítico de Bayly parte, claramente, das forças culturais locais e busca avaliar de que maneira eram aplicadas e também transformadas na convivência conflituosa com as imposições políticas e econômicas externas. Assim, a antropóloga britânica dá relevo às vozes e às atuações da elite local e aos usos estratégicos do saber local nas diversas tentativas de enfrentar o colonizador. Chama a atenção para o fato de que a maioria dos "modernisers" e "nationbuilders", frequentemente formada em instituições de ensino britânicas, teria concebido a casta como um fenômeno próprio de uma sociabilidade hindu particular: as opiniões divergiam, porém, sobre se as castas podiam ajudar ou atrapalhar a formação de uma identidade nacional. Na medida em que as castas eram reconhecidas como a unidade básica da sociabilidade indiana, para Bayly, tanto os líderes proto-nacionalistas quanto aqueles dos movimentos dos intocáveis teriam contribuído para "substancializá-las" e endossado partes do discurso orientalista.

\subsection{Foco: discursos coloniais estruturantes}

Já a análise de Nicholas Dirks ilumina, acima de tudo, a ação e o saber coloniais como forças primordiais responsáveis pelas 
transformações das castas na Índia. Um marco para a história de toda a região teria sido a grande revolta (Sepoy Mutiny) de 1857, quando um grupo de militares indianos ("sepoy") se rebelou contra o domínio da East India Company; a Coroa britânica reagiu a este choque com a dissolução da Companhia, impondo o "governo direto" ("direct rule") sobre a Índia. Para Dirks, essa decisão teve consequências fundamentais, já que deu início à instauração de um aparato administrativo colonial que logo se pôs a investir na produção de um conhecimento mais sistematizado sobre as populações locais: entendia-se que, para melhor administrar e controlar a colônia, era necessário obter informações mais precisas e seguras.

Dirks vê nesta atitude o início de um processo de antropologização do conhecimento que cumpria não somente objetivos estritamente administrativos, mas assumiria, com o tempo, um papel muito mais abrangente. Com a organização de amplos estudos censitários no final do século XIX, promovidos por administradores-antropólogos, a antropologia deixaria de ser um mero instrumento administrativo para transformar-se numa "episteme administrativa" (Dirks, 2001, p. 221). Os primeiros tijolos para a construção de um saber colonial já teriam sido colocados, de acordo com esta leitura pós-colonial, pelos estudos dos chamados orientalistas, sobretudo pelas pesquisas nas áreas da linguística e religião, a partir do final do século XVIII.

Boa parte das reflexões de Dirks é dedicada à análise do pensamento de cientistas como William Jones, Max Müller e Herbert Risley. A descoberta de Jones acerca de semelhanças linguísticas notáveis entre sânscrito, grego e latim, repercutiria sobre a maneira como os britânicos concebiam a relação entre a civilização europeia e as populações indianas, uma vez que boa parte dos cientistas europeus já partia da premissa de que existia uma congruência entre línguas e raças humanas. A detecção deste nexo provocou certos sentimentos de identificação e de aproximação, mas não sem que a posição de superioridade diante dos "irmãos indianos" fosse reafirmada. O objetivo de estudar sânscrito teria sido inicialmente outro: Jones queria fornecer à administração colonial o acesso a uma compilação de textos antigos (Manu Smrti - provavelmente escritos entre os séculos II ou III), que, 
de acordo com suas conviç̧ões, representavam um código de leis antigo. A ideia era reconstituir uma espécie de "texto primevo" ("Ur-Text") e aplicá-lo como uma "lei hindu" sem ter de depender da interpretação dos pandits (sábios hindus) (Cohn, 1996, p. 29).

Os estudos linguísticos de Jones que resultaram na descoberta posterior de um segundo tronco linguístico - as línguas dravidianas no sul da Índia abririam também o caminho para fundamentar uma teoria civilizatória indiana que se basearia num encontro entre duas raças. Foram acima de tudo os estudos de Max Müller que contribuíram fundamentalmente para o aprofundamento e aperfeiçoamento desta tese. Cerca de um século depois da tradução dos Manu Smrti, o filólogo e fundador das ciências comparadas da religião, Max Müller, iniciou a tradução do Rig Veda. Ele acreditava que este conjunto de textos sagrados, tidos na época como os escritos mais antigos do mundo, lhe daria acesso não somente aos fundamentos da teologia do povo hindu, mas ao fenômeno da religião como um todo. A diferenciação entre "arya" (literalmente "homem nobre e honrado") e "não arya" feita no Rig Veda foi um dos pontos de partida para Müller desenvolver suas teses. Inspirados nas revelações de Jones, Müller via nos "arya" os fundadores de um tronco linguístico (as línguas indo-europeias) cujo local de residência originária ele situou na Ásia central - baseandose nestas "descobertas", Müller sentia-se autorizado a usar o termo "arianos" (e também "'raça ariana") para designar este grupo originário. O estudioso teuto-britânico postulava ainda que os "arianos" eram gente branca e civilizada que se dividiram em dois ramos. Um, descrito como mais ativo e combativo, teria migrado para a Europa; já os arianos do sul, mais passivos e meditativos, teriam invadido o Irã e a Índia onde se defrontaram com uma população de cor de pele escura que acabou sendo subjugada pelo "povo mais avançado em civilização" ${ }^{30}$. Essa interpretação ficou conhecida como "teoria da invasão ariana".

Posteriormente, os trabalhos do antropólogo e administrador Risley contribuiriam para aprofundar o nexo entre casta e raça, sendo que a raça era concebida por este cientista como uma categoria biológica que determinaria todas as características e qualidades humanas. Base para suas reflexões eram os estudos censitários e as amplas pesquisas 
antropométricas. Assim, Risley buscava, por exemplo, comprovar uma correlação direta entre "índice nasal" e a divisão hierárquica da população no sistema de castas (Risley, 1908, p. 9). Esse antropólogo não tinha dúvida de que os brâmanes eram os descendentes dos indoarianos e apresentavam, portanto, um tipo racial mais avançado, de tez clara; já as castas inferiores tinham as características de um tipo racial mais primitivo que correspondia à população originária dravidiana. Desta maneira, este antropólogo-administrador endossou as linhas gerais da teoria da invasão ariana e acrescentou-lhe um novo detalhe. Ao subjugar as populações indígenas indianas, acreditava Risley, os conquistadores arianos teriam erigido um regime de segregação entre arianos e não arianos, inventando, assim, o sistema de castas. E Risley apresentou ainda uma explicação científica para esta atitude dos brâmanes: a razão profunda estaria num "sentimento racial", mais especificamente, numa antipatia natural das raças superiores frente a raças inferiores que visaria à preservação da pureza da população civilizada (Risley, 1891, p. XXXVIII; Dirks, 2001, p. 213).

Dirks ressalta, nas suas análises, a importância política que o raciocínio de Risley teve no contexto colonial. De um lado, contribuiu fundamentalmente para consolidar a ideia de que as castas hindus eram a base ("cimento") da sociabilidade indiana, de outro justificou a presença britânica na região. O alerta explícito de Risley de que uma dissolução do sistema de castas podia provocar um caos na Índia fez Dirks avaliar que este cientista-administrador defendeu as castas como um complemento necessário da autoridade governamental, como uma espécie de sociedade civil que garantiria a ordem no estado colonial (Dirks, 2001, p. 51).

Se Dirks dá claramente ênfase à força dos discursos orientalistas, não nega, ao mesmo tempo, também que as teses produzidas por Risley aproveitaram-se de e incorporaram partes importantes do saber brâmane, da mesma forma que Bayly reconhece amplamente o impacto das teses orientalistas sobre a substancialização da noção de casta na Índia. Ambos os estudos apresentam também análises sobre os pensamentos e ações dos primeiros pensadores nacionalistas (por exemplo, Vivekananda) e líderes dos intocáveis (por exemplo, Phule) que revelam diálogos e apropriações mútuas entre saber colonial e 
saber local: por exemplo, na maneira como Vivekananda fez uso da argumentação racional-científico, característica do mundo acadêmico ocidental, para construir a ideia de que existe uma espiritualidade hindu específica que une todos os indianos e caracterizá-la como moralmente superior ao materialismo ocidental; ou ainda nos discursos de Phule que reproduzia a ideia de os intocáveis serem descendentes da população originária invadida pelos arianos para declará-los legítimos donos da Índia e reivindicar que fossem protegidos pelo governo de todas as formas de discriminação.

Embora o leitor possa encontrar nos dois livros talvez mais convergências do que divergências entre as avaliações dos autores, Dirks e Bayly não escondem, nos seus posicionamentos teóricos, seus pontos de partida analíticos divergentes e fazem questão de apontar para falhas nas perspectivas analíticas dos/as colegas. Assim, Dirks critica duramente a Escola Histórica de Cambridge (cita especialmente Christopher Bayly - marido falecido de Susan Bayly - como representante mais importante desta interpretação da história indiana). O antropólogo norte-americano irrita-se com o teor dos estudos desta tradição britânica que, de acordo com ele, salienta fatores, tais como o estado anárquico após a implosão do Estado mughal, a subsequente fraqueza e instabilidade do domínio britânico, as divergências entre os administradores e cientistas britânicos nas suas avaliações da população local (ausência de um saber colonial uniforme e consolidado), para, desta forma, dar destaque à participação ativa e decisiva não apenas das elites, mas de boa parte da população indiana nas transformações do fenômeno social das castas. Tal perspectiva distorceria totalmente os papeis dos envolvidos na ampliação e petrificação do sistema hierárquico. Com a exclamação "Culpe a vítima novamente!", Dirks faz questão de explicitar seu protesto e vê no reconhecimento de um "agenciamento local" uma estratégia de transferir responsabilidades às vítimas do processo transformador:

E mais uma vez, agenciamento indiano - decisivo, não confiável e incognoscível ao mesmo tempo - emerge triunfante através da estrutura flácida do governo colonial, um tributo ao papel heroico dos indianos na construção do império britânico. (Dirks, 2001, p. 310) 
Susan Bayly, por sua vez, opõe-se enfaticamente àquelas interpretações ( sem citar explicitamente o termo pós-colonial) que, segundo ela, creditam o surgimento de um sistema de castas uniforme a ficções orientalistas e a discursos coloniais essencializantes; acusaos, portanto, de ignorar as tradições e os saberes locais (Bayly, 2001, p. 11, 366, 373). Bayly não nega o papel da intervenção britânica nas transformações que afetaram a concepção e a dimensão social das castas. No entanto, seria inadequado, na visão desta pesquisadora, julgar “[...] que a Índia viesse a aparentar ou comportar-se como uma sociedade de castas 'tradicional' pelo fato de os europeus assim a terem percebido e construído." (Bayly, 2001, p. 373).

\section{Considerações Finais}

Nenhum/a pesquisador/a sério/a duvida hoje de que as castas, tal como são representadas e vivenciadas na contemporaneidade, sejam um produto de uma confluência entre saber e ação coloniais e saber e ação locais. O que diferencia as análises são, acima de tudo, os pesos atribuídos, nestes processos de interpenetração, junção, oposição e apropriação mútua, às forças culturais locais, ao saber colonial e ao poder das instituições coloniais. As compreensões divergentes têm evidentemente a ver com olhares e enfoques teórico-metodológicos diferentes. Como entendo que tanto o enfoque antropológico quanto o pós-colonial permitem-nos acesso a dimensões importantes dos fenômenos socioculturais, acredito ser necessário investir no desenvolvimento de uma perspectiva analítica plural(izada).

Para tanto, é preciso reconhecer, entre outras coisas, as histórias particulares e os alcances e limitações analíticas de cada uma das "tradições" interpretativas. Ao reconhecer, por exemplo, que cultura como marcador de diferença e efeito do poder não é igual à cultura como fonte de cogniçãa e de valores societais, e que, ao mesmo tempo, cada uma destas concepções divergentes pode nos ajudar a iluminar aspectos importantes acerca da maneira como diferenças e desigualdades são articuladas e vivenciadas, cria-se as condições para operar em mais de um plano analítico simultaneamente. Ao invés de negar, encobrir ou borrar as diferenças entre enfoques teórico-metodológicos, de 
certo modo, antagônicos, parece-me ser mais fecundo tirar proveito tanto dos saberes antropológicos "mais clássicos" quanto das críticas pós-coloniais, de tal maneira que se torne possível construir cenários multifacetados daqueles fenômenos socioculturais que se pretende compreender e diante dos quais se quer posicionar.

Por último, gostaria ainda de fazer uma curta referência aos posicionamentos divergentes de Bayly e Dirks frente ao sistema de reservations (cotas, subsídios) na Índia contemporânea. Nenhum deles apoia este amplo sistema sem restrições; ambos veem nele nexos diretos com a política colonial que instituiu as primeiras listas de Scheduled Castes e Scheduled Tribes. No entanto, os comentários de Bayly são bem mais críticos do que os de Dirks. Ela não apenas denuncia a "lógica essencializante" do sistema; para ela, há uma incompatibilidade entre o combate a injustiças sociais e a promoção de direitos iguais para todos (tal como a Constituição indiana proclama), de um lado, e o aprofundamento da "lógica das castas" por meio de políticas de reservations, de outro (Bayly, 2001, p. 270, 316).

Dirks (2001) reconhece, de certa forma, que é difícil defender o sistema de reservations, já que este não rompe com a episteme colonial. Casta carrega, evidentemente, consigo a marca do passado colonial, afirma o autor. Mas na medida em que as castas continuam tendo relevância não somente como uma forma de discriminação e desigualdade, mas também como um eixo fundamental de mobilização e de luta por direitos, estas poderiam, sim, ser encaradas como um instrumento válido para construir um futuro diferente. É esse raciocínio que leva Dirks a proclamar que não se deve seguir as vozes conservadoras que querem apagar ou silenciar as castas num momento em que a casta se tornou a forma comunitária mais eficaz para ocupar espaços na vida política (Dirks, 2001, p. 295, 301, 314).

Acredito que por detrás desses posicionamentos é possível encontrar não somente convicções de ordem puramente ideológica. Expressam-se aqui também maneiras distintas de analisar diferenças e desigualdades. Bayly foca, em primeiro lugar, comportamentos implícitos e valores intrínsecos e pergunta-se, a partir daí, como uma política que usa as castas como critério de diferenciação pode contribuir 
para superar a "lógica das castas". Dirks preocupa-se, acima de tudo, com as desigualdades econômicas, sociais e políticas concretas e tende a explicar fenômenos socioculturais como o das castas a partir da imposição de discursos hegemônicos. Mais uma vez, vejo nestas posturas não apenas oposições insuperáveis, mas interpretações que têm, cada uma delas, sua validade e coerência internas. Para reconhecê-las em todas as suas dimensões, acredito ser preciso trabalhar com uma pluralidade de perspectivas analíticas, o que não parece ser tarefa fácil. Mais difícil ainda é inventar políticas públicas e construir práticas sociais que consigam incorporar a dualidade desses saberes: evitar a essencialização da(s) diferença(s) e, ao mesmo tempo, promover um espírito igualitário e antidiscriminatório.

\section{Notas}

1 Ao analisar a política britânica colonial, Rea afirma: “Nenhum patrocínio governamental formal da antropologia foi acessível até a década de 1930 e, mesmo então, a relação entre antropologia e autoridades coloniais era de cautela, ceticismo e desconfiança. Para os administradores coloniais, o antropólogo, com sua tendência de 'tornar-se nativo' ['going native'], era mais uma ameaça para a hegemonia da sociedade colonial branca [...]" (Rea, 2010, p. 185).

2 De acordo com Trouillot, os antropólogos não fizeram outra coisa a não ser imitar o "estado-centrismo" já amplamente praticado pelas ciências sociais vizinhas. Na medida em que as populações não-ocidentais eram pensadas como "fundamentalmente diferentes tanto em essência quanto na prática", surgia a necessidade de estudá-las com métodos distintos daqueles usados para as sociedades ocidentais e abria-se aos antropólogos a possibilidade de se posicionarem como „especialistas“ para o chamado "savage slot" (Trouillot, 2002, p. 42).

3 Trouillot (2002) argumenta que, embora na França e na Grã-Bretanha, a noção de „culturas" não tenha ganhado tanta importância - como unidade de análise (cf., por exemplo, a postura crítica de Radcliffe-Brown) - como nos EUA, os processos de essencialização e "fechamento" teriam sido fundamentalmente os mesmos: "Notadamente, na França e na Grã-Bretanha, eles [os antropólogos] enfatizaram notavelmente a rigidez de tais conceitos, como 'fato social total' e 'estrutura social', cada um dos quais supostamente conduziu a mente do observador a uma clausura. Nos Estados Unidos, 'cultura' promoveu um enclausuramento ainda mais denso" (Trouillot, 2002, p. 43).

4 Antes de Bastide, na obra de Herskovits já aparecem reflexões que associam a noção de resistência a determinadas tradições culturais atribuídas a populações colonizadas.

5 Foi somente com a Escola de Manchester que mudanças socioculturais locais ocorridas no contexto da intervenção colonial tornaram-se, de fato, objeto de estudo. Passariam ainda algumas décadas até que, segundo Reinhardt (2014, p. 346), se consolidasse uma tradição acadêmica construtivista, inspirada na diretriz analítica

ILHA

v. 19, n. 2, p. 37-71, dezembro de 2017 
da "invenção das tradições" (Hobsbawm; Ranger, 1983), que permitiu conceber o colonialismo não somente como uma questão meramente administrativa e/ou como um fator externo ao modo de vida dos colonizados. Somente na década de 1980 surge, no bojo destas reflexões, uma corrente chamada por alguns (Pels, 1997; Reinhardt, 2014) de "antropologia do colonialismo" que tenderia a abordar o colonialismo como uma espécie de foça generativa: de um lado, atribui-se à intervenção colonial uma dimensão ideológica e mesmo cultural; de outro, começa-se a pôr em xeque binarismos e questiona-se unidades representativas fechadas (tais como colonizadores e colonizados), na medida em que busca-se agora entender atitudes, posicionamentos, motivações e imaginários despertados no contexto do encontro colonial.

6 A crítica literária Mohanram concorda com a análise de Hall, na medida em que entende que "os estudos pós-coloniais se baseiam na constatação de que a história do colonialismo constitui-se na manutenção de limites claramente delineados entre o si mesmo (self) e o outro". Além disso, salienta o fato de que este processo foi acompanhado e impulsionado pela transformação do "si mesmo" ("Ocidente bran$\left.\mathrm{co}^{\prime \prime}\right)$ numa categoria não marcada, encobrindo assim o mecanismo que fez surgir as oposições binárias e processos de inferiorização: “O processo do colonialismo (e neocolonialismo) e a dominação do resto do mundo pelo Ocidente (branco) tem transformado este último em o si mesmo (branco) ocidental não marcado. [...] Este silenciamento e a não-marcação do si mesmo ocidental também o naturaliza efetivamente e borra os rastros do mecanismo de oposições binárias que postula o corpo não branco e não ocidental como o marcado e o visível" (Mohanram, 1999, p. 185).

7 A insistência na construção de uma perspectiva latina-americana própria e rejeição de autores ocidentais como referência fundante de um pensamento crítico são alguns dos argumentos recorrentes usados pelos auto-intitulados decoloniais para justificar um distanciamento dos pós-coloniais. Em decorrência de trajetórias intelectuais e de lutas políticas particulares, argumentos materialistas ganham frequentemente mais força do que nas análises dos pós-coloniais "clássicos" que são, em sua maioria, mais nitidamente marcados pela "virada linguística". Nem todos os comentadores concordam com a avaliação dos decoloniais. Assim, Kerner refere-se ao pensamento decolonial como "[...] um segmento das perspectivas pós-coloniais que emergiu com um explícito enfoque na história e nas experiências latino-americanas." (Kerner, 2016, p. 169). De forma parecida, numa introdução à teoria pós-colonial, as cientistas políticas Varela e Dhawan veem a oposição entre pós-coloniais e decoloniais como contraproducente. Elas criticam e rejeitam a ideia de as análises decoloniais serem mais radicais do que as pós-coloniais, na medida em que - assim soa o argumento decolonial - a primeira corrente seria menos eurocentrista e mais incisivamente anticapitalista (os decoloniais acusam os pós-coloniais ainda de não partirem, nas suas suas reflexoes, das lutas materialistas concretas) (Varela; Dhawan, 2015, p. $322,323)$.

8 Para o sociólogo porto-riquenho Grosfoguel (2006), as discussões pós-coloniais buscam revelar exatamente como o epistêmico e o colonial se constituem e influenciam mutuamente.

9 James Clifford comenta o foco do estudo de E. Said em Orientalismo da seguinte maneira: “A questão teórica fundamental levantada em 'Orientalismo' diz respeito ao status de todas as formas de pensamento e de representação relacionadas com o outro. Será que é possível escapar - em última instância - de procedimentos de 
dicotomização, de reestruturação, de textualização quando se faz afirmações (interpretativas) sobre culturas e tradições estrangeiras? Se é possível, como fazê-lo? Said reconhece abertamente que apresentar alternativas ao orientalismo não é seu objeto" (Clifford, 1988, p. 261).

10 A cientista política brasileira Luciana Ballestrin (2013, p. 90) lembra, nesse contexto, os fenômenos do patriarcado e da escravidão que, em diversos lugares do mundo, existiram antes da chegada dos europeus.

${ }^{11}$ Manuela Carneiro da Cunha distingue entre cultura sem aspas (modos de pensamento, estilos de vida, etc.) e cultura com aspas, uma espécie de metadiscurso autorreflexivo sobre a própria cultura que ganha importância sociopolítica num momento de intensificação das relações interétnicas ("regime de etnicidade"). Escreve Cunha: "As pessoas [...] tendem a viver ao mesmo tempo na 'cultura' e na cultura. Analiticamente, porém, essas duas esferas são distintas, já que se baseiam em diferentes princípios de inteligibilidade. A lógica interna da cultura não coincide com a lógica interétnica das 'culturas'” (2009, p. 359). A antropóloga brasileira chama ainda a atenção para o fato de que cultura (sem aspas) e "cultura" se afetam mutuamente: "O que estou sugerindo aqui é que a reflexividade tem efeitos dinâmicos tanto sobre aquilo que ela reflete - cultura, no caso - como sobre as próprias metacategorias, como 'cultura'" (2009, p. 363).

12 Com os conceitos "identidades imperativas" e "situacionais" (ou ainda "escolhidas"), Eriksen busca chamar a atenção para diferentes modos que detectou nos processos identitários. Ele recorda o fato de que, no caso das identificações imperativas (que geralmente dizem respeito aos laços de parentesco, à identificação com a língua mãe, mas também ao pertencimento a uma comunidade religiosa), a margem de negociação é bem menor do que na das chamadas situacionais (Eriksen, 2004, p. 161). Alguns antropólogos, por exemplo, Jenkins (1997, p. 81), chamam ainda a atenção para o fato de que as autoidentificações (identidades autogeradas) não coincidem necessariamente com as categorizações criadas e atribuídas por outros (identidades impostas). Tal diferenciação tem frequentemente uma grande relevância em contextos coloniais.

13 Escreve Hall: "Identidades culturais são pontos de identificação, os pontos instáveis de identificação ou suturas, que são construídas dentro dos discursos da história e da cultura. Não são uma essência, mas um posicionamento" (Hall, 1990, p. 226). Hall e outros pós-coloniais argumentam que são os discursos que produzem um lugar para o sujeito: abrem um espaço para um posicionamento e reposicionamento dos sujeitos. No fundo, este sociólogo de origem jamaicana entende que sujeitos e discursos constituem-se simultaneamente; ou melhor, que indivíduos e coletivos só podem se articular por meio de discursos.

14 Afirma Eriksen: "Podemos optar por não falar de tais particularidades do cotidiano e da realidade social em termos de 'cultura', mas elas não são nem mais nem menos inventadas ou reais do que qualquer outra coisa. As pessoas não escolhem seus parentes, não podem optar por livrar-se de sua infância e de tudo que aprenderam numa idade tenra. Estes são aspectos da identidade que não são escolhidos; são incorporados e implícitos" (Eriksen, 2002, p. 5).

15 Num outro texto, Dirks afirma: “O conceito antropológico de cultura nunca poderia ter sido inventado se não tivesse havido um teatro colonial que tanto exigia o conhecimento das culturas para propósitos de controle e dominação) quanto proporcionava uma circunscrição colonizada que era particularmente acessível à cultura. Sem o colonialismo, a cultura não poderia ter sido ao mesmo tempo (e 
com tanto êxito) organizada e organizadora [...]. Não apenas muito daquilo que chamamos 'cultura' foi produzido pelo encontro colonial como o conceito mesmo de cultura foi em parte inventado por causa desse encontro" (Dirks, 1992, p. 3).

16 Escreve Abu-Lughod: "Cultura é a ferramenta essencial para a fabricação do outro" (Abu-Lughod, 1991, p. 143).

${ }^{17}$ Cf. as palavras de Ortner: "[...] Spivak e outros que operam com um tipo de análise pós-estruturalista (principalmente, derridariana) chegam ao outro extremo, na medida em que dissolvem totalmente o sujeito num conjunto de 'efeitos subjetivos' que não têm virtualmente nenhuma coerência" (Ortner, 2006, p. 54).

${ }^{18}$ Afirma Sahlins: "Essa redução funcional da cultura a um diferenciamento [differencing] - mediante uma redução de seu conteúdo a seus supostos efeitos, e de suas propriedades a suas pretensas finalidades - termina por dissolver praticamente tudo que a antropologia busca saber, e que o trabalho de campo luta por descobrir, sobre as culturas humanas enquanto formas de vida" (Sahlins, 1997, p. 43-44). "Instituições sociais, modos de produção, valores de objetos, categorizações da natureza e o resto - as ontologias, epistemologias, mitologias, teologias, escatologias, sociologias, políticas e economias através das quais os povos organizam a si mesmos e aos objetos de sua existência -, tudo isso se vê reduzido a um mero aparato pelo qual as sociedades ou grupos se distinguem uns dos outros" (Sahlins, 1997, p. 44). E, paradoxalmente, as criticadas noções homogeneizantes e holísticas atribuídas pela antropologia clássica à cultura reaparecem, de acordo com Sahlins, na maneira como o capitalismo é abordado por estes críticos: "Em um curioso paradoxo pósmodernista, a Grande Narrativa do Sistema Mundial se torna o último refúgio da noção de cultura enquanto ordem monológica e determinista" (Sahlins, 1997, p. 55).

19 Há também antropólogos, como Lentz, que concordam com as críticas pós-coloniais ao conceito clássico de cultura; entretanto, ao invés de abandonar o termo, procuram reconceituá-lo, uma vez que veem nele um potencial analítico não contemplado por outros conceitos. Assim, Lentz propõe uma noção de cultura que consiga dar conta não apenas dos processos de "enclausuramento social" ("social closure") e das autoconcepções, mas também do congelamento de certas distinções em forma de configurações culturais estáveis: "Ambos os campos, o social e o cultural, exigem atenção não tanto no que diz respeito a unidades circunscritas, mas no que diz respeito à contingência do processo de construção de fronteiras, isto é: processos de emergência, estabilização e fechamento como também de desestabilização e dissolução. A antropologia precisa, portanto, indagar como as diferenças são construídas, i.é., estudar processos de diferenciação e não somente assumir diferenças como fatos ontológicos" (Lentz, 2016, p. 17).

20 Esta crítica já foi levantada por Asad na sua obra clássica Anthropology and the Colonial Encounter (1973).

${ }^{21}$ Apenas no subitem "Minorias, párias e características organizacionais da periferia" Barth faz uma referência genérica às minorias cuja situação descreve como „uma variante especial das relações interétnicas": "Penso que, na maioria dos casos, tais situações apareceram como um resultado de eventos históricos externos" (Barth, 1969, p. 3).

22 Esta concepção pode ser entendida como uma reprodução do ideal do Estado Nação Moderno que pressupõe uma identidade entre território, povo e língua. Cf. as críticas de Trouillot e Lentz a respeito do "nacionalismo metodológico".

${ }^{23}$ O Rig Veda (compilado entre 1.700 e 1.100 a.C.) faz referência a quatro varnas, fixando assim uma diferenciação social fundamental: os brâmanes ou sacerdotes;

ILHA

v. 19, n. 2, p. 37-71, dezembro de 2017 
os vaixás (comerciantes e proprietários de terra); os sudras (serviçais, artesãos e trabalhadores). Os três primeiros varnas eram considerados "arya" ("puros") e habilitados a participar dos rituais védicos; já os sudras, vistos como "não arya", eram excluídos dos ritos.

${ }^{24}$ Gandhi diferenciava entre casta como sistema social que, para ele, nada tinha a ver com o mundo religioso, e a lei de varna ("varnashramadharma"), os verdadeiros princípios religiosos e morais que se baseavam nos vedas e em outros escritos antigos (Gandhi, 1934, p. 260-61). Para Gandhi, esse modelo mítico (varnashramadharma) não apenas atribuiu a cada casta sua função, seus direitos e deveres, mas conferiu também a todos os grupos o mesmo valor e o mesmo status. As desigualdades seriam decorrência de deturpações históricas que teriam de ser revertidas por meio de uma revitalização dos fundamentos moral-religiosos hindus. Gandhi apostava, consequentemente, na "conscientização" das castas altas, apelando para que seus membros assumissem tarefas e trabalhos considerados "impuros" (por exemplo, limpar banheiros) e tratassem os intocáveis como iguais.

${ }^{25}$ Há uma longa discussão sobre a história do hinduísmo. Mais uma vez, podese perceber neste debate uma oposição entre as análises que descrevem uma longa tradição de valores religiosos e morais e aquelas avaliações que chamam a atenção para transformações profundas ocorridas no contexto da intervenção, que é responsabilizada, nestas análises, pela própria elaboração de uma religião coesa e uniforme à qual, posteriomente, teria dado o nome de hinduísmo (por exemplo, as contribuições para o livro: Bloch, Esther; Keppens, Marianne e Hedge, Rajaram (Org.). Rethinking Religion in India: The Colonial Construction of Hinduism, 2010; cf. tb. Van der Veer, 2001, p. 24-30).

${ }^{26}$ Esta atitude tinha levado Ambedkar, já em 1927, a queimar publicamente, diante de milhares de seguidores, uma cópia do chamado Manu Smrti, um ato dramático que provocou a indignação de muitos reformistas hindus. Ambedkar teria dito que o ato de por fogo no documento representava a aniquilação de um "símbolo da injustiça que nos tem esmagado ["crushed"] durante séculos" (apud Bayly, 2001, p. 259). O dia em que Ambedkar queimou o Manu Smrti (25 de dezembro) continua sendo celebrado anualmente por seguidores de Ambedkar como "Manu Smriti Burning Day".

27 Os varnas constituem até hoje um esquema ordenador de referência fundamental; além disso, há as milhares de jatis - "subcastas" - que orientam, na vida cotidiana, as interações sociais. O termo português casta fundiria varna e jati.

${ }^{28}$ Escreve Dirks: “Na Índia pré-colonial, havia múltiplas unidades de identidade social, cujas respectivas relações e trajetórias faziam parte de um mundo político complexo e conjuntural em constante mutação. As referências à identidade social não eram apenas heterogêneas: eram também determinadas pelo contexto. Comunidades de templos, grupos territoriais, segmentos de linhagens, unidades familiares, cortejos reais, subcastas de guerreiros, 'pequenos' reinos, grupos ocupacionais de referência, associações agrícolas ou comerciais, redes de devoção e comunidades sectárias, inclusive sociedades cabalísticas sacerdotais, eram apenas algumas das unidades significativas de identificação, todas elas em diversos momentos muito mais importantes que qualquer metonímia uniforme de agrupamentos de 'casta' endogâmicos" (Dirks, 2001, p. 13).

29 No fim de sua vida, Müller fez, aparentemente, um esforço para distanciar-se de certos "exageros" de suas teses, reconhecendo que é impossível constatar uma congruência entre raça e língua (Trautmann, 1997, p. 196). 


\section{Referências}

ABU-LUGHOD, Lila. Writing against culture. In: FOX, Richard (Org.). Recapturing anthropology: working in the present. Santa Fe, New Mexico: School of American Research Press, 1991. p. 137-162.

AMBEDKAR, Bhimrao Ramji. Annihilation of Caste. Bombay: B.R. Kadrekar, 1936.

ASAD, Talal. Anthropology and the Colonial Encounter. London: Ithaca Press, 1973.

BALLESTRIN, Luciana. América Latina e o giro decolonial. Revista Brasileira de Ciência Política, [S.l.], v. 11, p. 89-117, 2013.

BEER, Bettina. Körperkonzepte, interethnische Beziehungen, Rassismustheorien, Berlin: Dietrich Reimer, 2002.

BARTH, Fredrik. Introduction. In: BARTH, Fredrik (Org.). Ethnic groups and boundaries. Bergen: Universitetsforlaget, 1969. p. 9-38.

BASTIDE, Roger. Les religions africaines au Brésil. Paris: PUF, 1960.

BAYLY, Susan. Caste, society and politics in India from the eighteenth century to the Modern Age. Cambridge: Cambridge University Press, 2001 [1999].

BHABHA, Homi. The Location of Culture. London: Routledge, 1994.

BLOCH, Esther; KEPPENS, Marianne; HEDGE, Rajaram (Org.).

Rethinking Religion in India: The Colonial Construction of Hinduism. London, New York: Routledge, 2010.

BOAS, Franz. A formação da antropologia americana: 1883-1911. Rio de Janeiro: Editora UFRJ, 2004.

CARVALHO, José Jorge de. O olhar etnográfico e a voz subalterna. Horizontes Antropológicos, [S.l.], ano 7, n. 15, p. 107-147, 2001.

CASTRO-GÓMEZ, Santiago. Latinoamericanismo, modernidad, globalización. Prolegómenos a una critica poscolonial de la razón. In: CASTRO-GÓMEZ, Santiago; MENDIETA, Eduardo (Org.), Teorías sin disciplina: Latinoamericanismo, poscolonialidad yglobalización en debate. [s.n.]: [S.l.], 1998, p. 169-205.

CLIFFORD, James. The predicament of culture. Cambridge: Harvard University Press, 1988.

COHN, Bernard S. Colonialism and its forms of knowledge. The British in India. Princeton: Princeton University Press, 1996.

COSTA, Sérgio. Dois atlânticos: teoria social, antirracismo, cosmopolitismo. Belo Horizonte: Ed. UFMG, 2006. 
CUNHA, Manuela Carneiro da. Cultura com aspas e outros ensaios de antropologia. São Paulo: Cosacnaify, 2009.

DIRKS, Nicholas. Colonialism and Culture. Ann Arbor: The University of Michigan Press, 1992.

DIRKS, Nicholas. Castes of mind: colonialism and the making of modern India. Princeton: Princeton University Press, 2001.

DOUGLAS, Mary. Edward Evans-Pritchard. New York: The Viking Press, 1980.

DURKHEIM, Émile e MAUSS, Marcel. De quelques formes de classification: Contribution à l'étude des représentations collectives.

Année sociologique, [S.l.], v. 6, p. 3-46, 1903.

ERIKSEN, Thomas Hylland. Confessions of a useful idiot, Or, Why culture should be brought back in. LBC Newsletter (Uppsala University), [S.l.], p. 1-8, 2002.

ERIKSEN, Thomas Hylland. What is anthropology? London: Pluto Press, 2004.

GANDHI, Mohandas Karamchand. Caste v. Class. Young India, India, v. 29, n. 12, p. 3, 1920.

GANDHI, Mohandas Karamchand. Fourfold division of Society and four stages of life. Harijan, [S.l.], v. 28-29, p. 260-261, 1934.

GROSFOGUEL, Ramon. La descolonización de la economía política y los estudios poscoloniales: transmodernidad, pensamiento fronterizo y colonialidad global. Tabula Rasa. Revista de Humanidades, [S.l.], v. 4, p. 17-48, 2006.

GUPTA, Akhil; FERGUSON, James. Space, identity, and the politics of difference. Cultural Anthropology, [S.l.], v. 7, p. 6-23, 1992.

HALL, Stuart. Cultural Identity and Diaspora. In: RUTHERFORD, Jonathan (Org.). Identity: Community, Culture, Difference. London: Lawrence \& Wishart, 1990. p. 222-237.

HALL, Stuart. A identidade cultural na pós-modernidade. Rio de Janeiro: DP\&A, 2001.

HALL, Stuart. Quando foi o pós-colonial? Pensando no limite. In: HALL, Stuart. Da diáspora: identidades e mediações culturais. Belo Horizonte: Editora UFMG, 2003. p. 101-128.

JENKINS, Richard. Rethinking Ethnicity: Arguments and Explorations. London: Sage Publications, 1997.

KERNER, Ina. La teoria postcolonial como teoria crítica global. Devenires, [S.l.], ano XVII, v. 34, p. 157-185, 2016. 
KUKLICK, Henrika. The savage within: the social history of British Anthropology, 1885-1945. Cambridge: Cambridge University Press, 1991.

LENTZ, Carola. Culture. The making, unmaking and remaking of an anthropological concept. Arbeitspapiere des Instituts für Ethnologie und Afrikastudien, Johannes Gutenberg Universität, Mainz, p. 1-24, 2016.

MALINOWSKI, Bronislaw. A diary in the strict sense of the term. Cambridge: Cambridge University Press, 1967.

MIGNOLO, Walter. Historias locales/diseños globales: colonialidade, conocimientos subalternos y pensamiento fronterizo. Madrid: Ediciones Akal, 2003.

MOHANRAM, Radhika. Black body: women, colonialism, and space. Minneapolis: University of Minnesota Press, 1999.

ORTNER, Sherry. Anthropology and social theory: culture, power, and the acting subject. London: Duke University Press, 2006.

PELS, Peter. The Anthropology of Colonialism: culture, history, and the emergence of Western governmentality. Annual Review of Anthropology, [S.l.], v. 26, p. 163-183, 1997.

PINNEY, Christopher. Colonialism and Culture. In: BENNETT, Tony e FROW, John Frow (Org.). The SAGE Handbook of Cultural Analysis. New York: Sage, 2008. p. 382-405.

QUIJANO, Aníbal. Antologías. Cuestiones y horizontes - de la dependencia histórico-estructural a la colonialidad/descolonialidad del poder. In: QUIJANO, Aníbal. (Org.). Colonialidad del poder y clasificación social. Argentina: CLACSO, 2014. p. 285-327.

REA, Will. Anthropology and Postcolonialism. In: CHEW, Shirley; RICHARDS, David (Org.). A concise companion to postcolonial literature. Oxford: Blackwell, 2010, p. 182-203.

REINHARDT, Bruno. Poder, história e coetaneidade: os lugares do colonialismo na antropologia sobre a África. Revista de Antropologia, [S.l.], v. 57, n. 2, p. 329-375, 2014.

RESTREPO, Eduardo. Antropología y colonialidad. 2017. p. 1-13. Disponível em: <http://www.ram-wan.net/restrepo/documentos/ antropologia\%20y\%20colonialidad.pdf>. Acesso em: 22 abr. 2017.

RISLEY, Herbert Hope. The Castes and Tribes of Bengal. Calcutta: Bengal Secretariat Press, 1891. v. 1.

RISLEY, Herbert Hope. The People of India. New Delhi: Munshiram Manoharlal Publishers, 1908. 
SAHLINS, Marshall. O "pessimismo sentimental" e a experiência etnográfica: por que a cultura não é um "objeto" em via de extinção (parte I). Mana, Rio de Janeiro, v. 3, n. 2, p. 41-73, 1997.

SAHLINS, Marhall. Waiting for Foucault, still. Chicago: Prickly Paradigm Press, 2002.

SAID, Edward. Orientalism. New York: Pantheon Books, 1978.

SANTOS, Boaventura Sousa. Do pós-moderno ao pós-colonial: e para além de um e outro. In: CONFERÊNCIA DE ABERTURA DO VIII CONGRESSO LUSO-AFRO-BRASILEIRO DE CIÊNCIAS SOCIAIS, Coimbra, 16-18 de setembro de 2004. Anais... Coimbra, 2004. p. 1-45. Disponível em: $<$ http://www.ces.uc.pt/misc/Do_pos-moderno_ao_pos-colonial.pdf $>$. Acesso em: 29 mar. 2017.

TRAUTMANN, Thomas. Aryans and British India. Berkely: University of California Press: 1997.

TROUILLOT, Michel-Rolph. Adieu, culture: a new duty arises. In: FOX, Richard G.; KING, Barbara J. (Org.). Anthropology beyond culture. Oxford: Berg, 2002, p. 37-60.

VARELA, María do Mar Castro; DHAWAN, Nikita. Postkoloniale Theorie: Eine kritische Einführung. Bielefeld: transcript, 2015.

VEER, Peter van der. Imperial encounters: Religion and modernity in India and Britain. Princeton: Princeton University Press, 2001.

Recebido em 26/09/2017

Aceito em 04/10/2017 